\title{
PERANCANGAN KENDALI PADA SISTEM EMPAT TANGKI MENGGUNAKAN TEKNIK KENDALI MODEL PREDIKTIF
}

\author{
Zaiful Ulum ${ }^{1}$ \\ ${ }^{1}$ STKIP PGRI Bangkalan \\ saifululum63@gmail.com
}

\begin{abstract}
ABSTRAK
Sistem empat tangki adalah sebuah plant laboratorium yang dirancang untuk menguji proses teknik kendali dan telah banyak diaplikasikan dalam dunia industri. Masalah pada sistem empat tangki tersebut adalah bagaimana mengendalikan level air pada keempat tangki sesuai dengan level yang diinginkan dengan cara memanipulasi debit pompa yang masuk pada setiap tangki. Pada paper ini disajikan perancangan kendali pada sistem empat tangki menggunakan pengendali model prediktif. Tujuan kendali adalah untuk membawa level air pada setiap tangki menuju level yang diinginkan dengan cara memanipulasi debit pompa yang masuk pada setiap tangki. Metode yang digunakan pada penelitian ini adalah studi literatur dan simulasi. Hasil simulasi memunjukkan bahwa level air pada setiap tangki mampu dibawa menuju level yang diinginkan. Lebih jauh lagi, debit pada setiap pompa berada pada batasan yang diperbolehkan. Hal ini memunjukkan bahwa pengendali model prediktif memiliki performa yang bagus dalam megendalikan sistem empat tangki.
\end{abstract}

Kata Kunci: Sistem empat tangki, pengendali model prediktif

\section{Pendahuluan}

Masalah kendali pada sistem empat tangki memiliki peranan yang sangat penting dalam aplikasi industri seperti industri pembuatan kertas, industri pembuatan makanan, dan industri petrokimia [6]. Masalah utama dalam aplikasi industri adalah bagaimana mengendalikan level air pada setiap tangki yang akan melewati beberapa proses agar tetap berada pada level yang diinginkan [2]. Untuk mencapai tujuan tersebut maka harus dirancang suatu sistem kendali menggunakan pengendali yang tepat.

Pada [6] digunakan pengendali LQR dan PID pada sistem dua tangki. Sedangkan pada [2] dirancang kendali pada sistem empat tangki menggunakan kontroler jaringan saraf tiruan (JST). Namun demikian, pengendali-pengendali tersebut masih memiliki kekurangan salah satunya adalah tidak memperhatikan secara eksplisit batasan/kendala sistem dalam menghitung kendali optimal. Hal ini membuat pengendali-pengendali tersebut kurang cocok diaplikasikan pada sistem yang ada di lapangan karena sistem yang ada umumnya memiliki batasan/kendala.

Kendali model prediktif merupakan salah satu teknik kendali optimal yang menggunakan model sistem untuk memprediksi keluaran sistem sepanjang horison berhingga dan prinsip horison mundur [3]. Input kendali pada setiap waktu sampling diperoleh dengan cara, (1) memprediksi keluaran sistem sepanjang horison berhingga menggunakan model sistem; (2) menyelesaikan masalah kendali optimal diskrit sepanjang horison berhingga pada setiap waktu sampling yang menghasilkan barisan kendali optimal; (3) berdasarkan barisan kendali optimal yang diperoleh, hanya elemen pertama dari barisan tersebut yang diaplikasikan pada sistem. Untuk waktu sampling berikutnya, input kendali dihitung dengan 
cara yang sama seperti pada waktu sampling sebelumnya. Hanya saja masalah kendali optimal yang harus diselesaikan diformulasikan kembali berdasarkan data yang diperoleh pada waktu sampling sebelumnya. Kelebihan teknik kendali ini adalah mampu mengendalikan sistem yang melibatkan banyak input dan output serta memperhatikan secara eksplisit batasan/kendala sistem dalam menghitung kendali optimal [7]. Lebih jauh lagi beberapa penelitian menunjukkan bahwa pengendali model prediktif memiliki performa yang lebih baik dibandingkan dengan kontroler PID [4,5] . Oleh karena itu, pada penelitian dirancang kendali pada sistem empat tangki menggunakan kontroler model prediktif.

Paper ini disusun menjadi lima bagian. Bagian 1 menjelaskan tentang beberapa penelitian tentang perancangan kendali pada sistem empat tangki yang telah dilakukan serta latar belakang perancangan kendali pada sistem empat tangki menggunakan pengendali kendali model prediktif. Pada Bagian 2 dijelaskan tentang model sistem empat tangki yang digunakan serta persamaan dinamisnya. Perancangan kendali pada sistem empat tangki menggunakan pengendali model prediktif diberikan pada Bagian 3. Untuk mengetahui unjuk kerja percangan kendali yang telah dilakukan dilakukan simulasi menggunakan Matlab yang disjaikan pada Bagian 4. Akhirnya, kesimpulan dan rencana penelitian selanjutnya diberikan pada Bagian 5.

\section{Persamaan Dinamis Sistem Empat Tangki}

Model sistem empat tangki yang digunakan pada penelitian ini diadopsi dari [1] seperti terlihat pada Gambar 1.

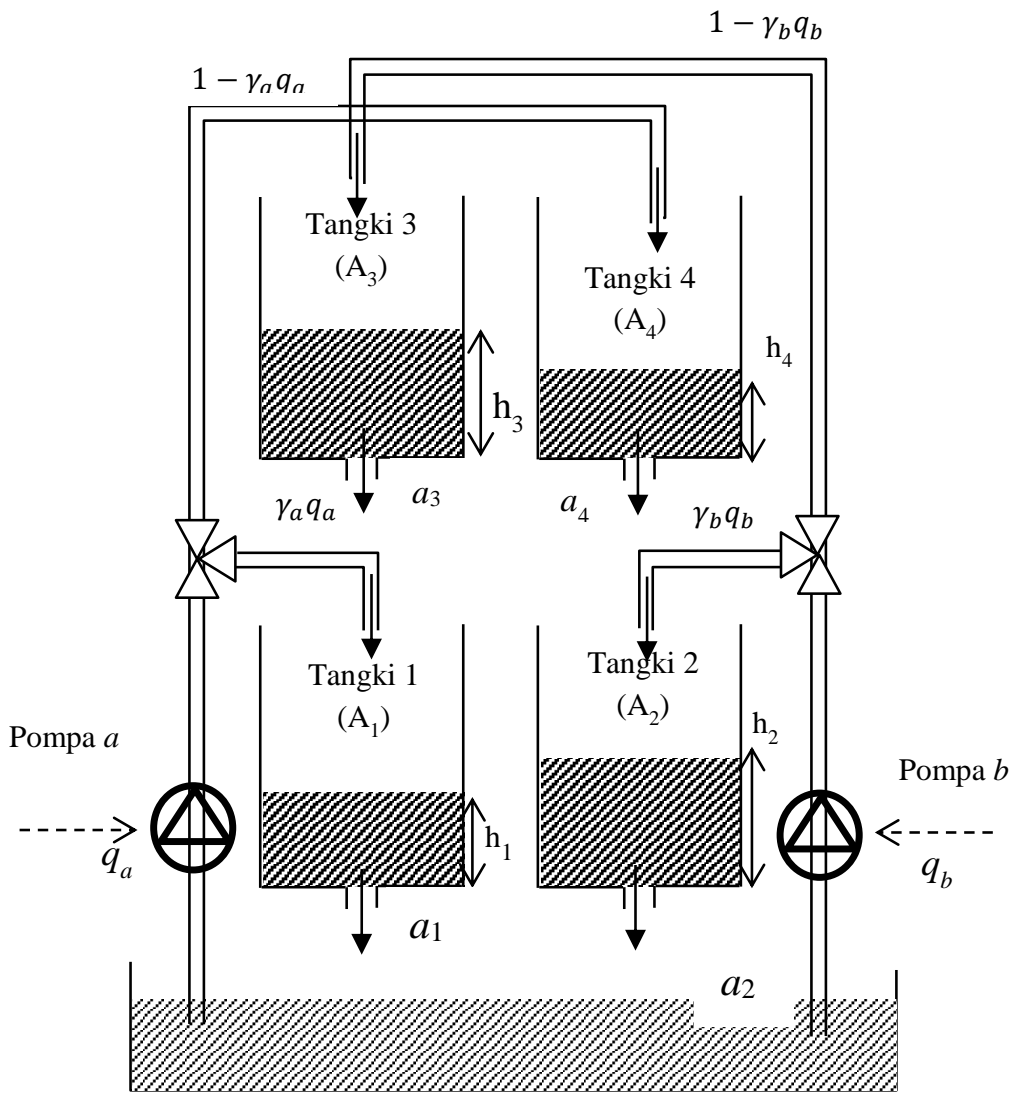

GAMBAR 1 Skema Sistem Empat Tangki

Nilai parameter sistem empat tangki di atas diberikan oleh Tabel 1 berikut. 
TABEL 1. Nilai-Nilai Parameter Sistem Empat Tangki

\begin{tabular}{|c|c|c|c|}
\hline & Nilai & Satuan & Deskripsi \\
\hline$h_{\max }$ & 1.36 & $\mathrm{~m}$ & Tinggi maksimum air pada tangki \\
\hline$h_{\min }$ & 0.2 & $\mathrm{~m}$ & Tinggi minimum air pada tangki \\
\hline$q_{\max }$ & 3.26 & $\mathrm{~m}^{3} / \mathrm{jam}$ & Debit maksimum $q_{a}$ dan $q_{b}$ \\
\hline$q_{\min }$ & 0 & $\mathrm{~m}^{3} / \mathrm{jam}$ & Debit minimum $q_{a}$ dan $q_{b}$ \\
\hline $\begin{array}{l}a_{1}, a_{2} \\
a_{3}, a_{4}\end{array}$ & $1.31 \times 10^{-4}$ & $\mathrm{~m}^{2}$ & Luas permukaan aliran keluar tangki \\
\hline $\begin{array}{l}A_{1}, A_{2} \\
A_{3}, A_{4}\end{array}$ & 0.06 & $\mathrm{~m}^{2}$ & Luas permukaan tangki \\
\hline$\gamma_{a}, \gamma_{b}$ & 0.3 & & Proporsi aliran $q_{a}$ dan $q_{b}$ \\
\hline$h_{1}^{0}$ & 0.6042 & $\mathrm{~m}$ & Level ekuilibrium tangki 1 \\
\hline$h_{2}^{0}$ & 0.6042 & $\mathrm{~m}$ & Level ekuilibrium tangki 2 \\
\hline$h_{3}^{0}$ & 0.296 & $\mathrm{~m}$ & Level ekuilibrium tangki 3 \\
\hline$h_{4}^{0}$ & 0.296 & $\mathrm{~m}$ & Level ekuilibrium tangki 4 \\
\hline$q_{a}^{0}, q_{b}^{0}$ & 1.63 & $\mathrm{~m}^{3} / \mathrm{jam}$ & Debit ekuilibrium $q_{a}$ dan $q_{b}$ \\
\hline
\end{tabular}

Persamaan dinamis sistem empat tangki di atas diberikah oleh [1]

$$
\begin{gathered}
\frac{d h_{1}(t)}{d t}=-\frac{a_{1}}{A_{1}} \sqrt{2 g h_{1}(t)}+\frac{a_{3}}{A_{1}} \sqrt{2 g h_{3}(t)}+\frac{\gamma_{a}}{A_{1}} q_{a}(t), \\
\frac{d h_{2}(t)}{d t}=-\frac{a_{2}}{A_{2}} \sqrt{2 g h_{2}(t)}+\frac{a_{4}}{A_{2}} \sqrt{2 g h_{4}(t)}+\frac{\gamma_{b}}{A_{2}} q_{b}(t), \\
\frac{d h_{3}(t)}{d t}=-\frac{a_{3}}{A_{3}} \sqrt{2 g h_{3}(t)}+\frac{\left(1-\gamma_{b}\right)}{A_{3}} q_{b}(t), \\
\frac{d h_{4}(t)}{d t}=-\frac{a_{4}}{A_{4}} \sqrt{2 g h_{4}(t)}+\frac{\left(1-\gamma_{a}\right)}{A_{4}} q_{a}(t) .
\end{gathered}
$$

\section{Perancangan Kendali Menggunakan Pengendali Model Prediktif}

Untuk merancang sistem kendali menggunakan teknik kendali model prediktif, model prediksi sistem dan fungsi tujuan yang digunakan dalam desain kendali memiliki peranan yang sangat penting agar menghasilkan sistem kendali yang bagus. Pada bagian ini disajikan penurunan model prediksi sistem, perumusan fungsi tujuan, dan hasil simulasi perancangan kendali menggunakan Matlab.

Model prediksi yang digunakan pada penelitian ini adalah persamaan state space linear time invariant waktu diskrit. Untuk memperoleh model prediksi tersebut, persamaan dinamis sistem empat tangki (1) dilinearisasi di sekitar titik ekuilibrium $\left(h_{1}^{0}, h_{2}^{0}, h_{3}^{0}, h_{4}^{0}, q_{a}^{0}, q_{b}^{0}\right)$. Setelah persamaan (1) dilinearisasi, dilanjutkan dengan diskritisasi persmaan linear yang diperoleh dengan menggunakan waktu sampling $T_{s}$. Bentuk linear persamaan (1) diberikan oleh 


$$
\dot{x}(t)=A x(t)+B u(t)
$$

$$
\begin{aligned}
& \text { dengan } x(t)=\left[\begin{array}{lrrr}
x_{1}(t) & x_{2}(t) & x_{3}(t) & x_{4}(t)
\end{array}\right]^{T}, u(t)=\left[\begin{array}{ll}
u_{1}(t) & u_{2}(t)
\end{array}\right]^{T}, x_{i}(t)=h_{i}(t)- \\
& h_{i}^{0}, u_{1}(t)=q_{a}(t)-q_{a}^{0}, u_{2}(t)=q_{b}(t)-q_{b}^{0}, \tau_{i}=\frac{A_{i}}{a_{i}} \sqrt{\frac{2 h_{i}^{0}}{g}, i=1,2,3,4 \text {, dan }} \\
& A=\left[\begin{array}{cccc}
-\frac{1}{\tau_{1}} & 0 & \frac{1}{\tau_{3}} & 0 \\
0 & -\frac{1}{\tau_{2}} & 0 & \frac{1}{\tau_{4}} \\
0 & 0 & -\frac{1}{\tau_{3}} & 0 \\
0 & 0 & 0 & -\frac{1}{\tau_{1}}
\end{array}\right], B=\left[\begin{array}{ccc}
\frac{\gamma_{a}}{A_{1}} & 0 \\
0 & \frac{\gamma_{b}}{A_{2}} \\
0 & \frac{\left(1-\gamma_{b}\right)}{A_{3}} \\
\frac{\left(1-\gamma_{a}\right)}{A_{4}} & 0
\end{array}\right] .
\end{aligned}
$$

Vektor $x$ dan $u$ pada persamaan (2) di atas menyatakan vektor state dan input sistem. Pada penelitian ini vektor state $x$ diambil sebagai output sistem.

Bentuk diskrit (2) dengan waktu sampling $T_{s}=1 \mathrm{~s}$ diberikan oleh persamaan berikut.

$$
x(k+1)=A_{d} x(k)+B_{d} u(k),
$$

dengan $k$ menyatakan waktu diskrit dan

$$
A_{d}=\left[\begin{array}{cccc}
0.9938 & 0 & 0.0088 & 0 \\
0 & 0.9938 & 0 & 0.0088 \\
0 & 0 & 0.9912 & 0 \\
0 & 0 & 0 & 0.9938
\end{array}\right], B_{d}=\left[\begin{array}{cc}
4.9845 & 0.0516 \\
0.0516 & 4.9845 \\
0 & 11.6150 \\
11.6305 & 0
\end{array}\right] .
$$

Matriks $A_{d}$ dan $B_{d}$ di atas diperoleh dengan menggunakan bantuan sofware Matlab dengan perintah $\mathrm{c} 2 \mathrm{~d}(A, B, 1)$, dengan $A$ dan $B$ adalah matriks pada persamaan (2) dan 1 menyatakan waktu sampling. Persamaan (3) inilah yang akan dijadikan sebagai model prediksi sistem. Misalkan $\hat{x}(k+j \mid k)$ dan $\hat{u}(k+j \mid k)$ menyatakan prediksi state dan input sistem (3) pada waktu sampling $k+j, j \geq 0$, berdasarkan informasi pada saat $k$ dengan asumsi bahwa $\hat{x}(k \mid k)=x(k)$. Prediksi state sepanjang horison prediksi $H_{p}$, pada penelitian ini $H_{p}=5$, diberikan oleh

$$
X(k)=\bar{A} x(k)+\bar{B} U(k),
$$

dengan

$$
\begin{aligned}
& X(k)=\left(\begin{array}{lllll}
\hat{x}(k+1 \mid k) & \hat{x}(k+2 \mid k) & \hat{x}(k+3 \mid k) & \hat{x}(k+4 \mid k) & \hat{x}(k+1 \mid k))^{T},
\end{array}\right. \\
& U(k)=\left(\begin{array}{lllll}
\hat{u}(k \mid k) & \hat{u}(k+1 \mid k) & \hat{u}(k+2 \mid k) & \hat{x}(k+3 \mid k) & \hat{x}(k+4 \mid k))^{T},
\end{array}\right.
\end{aligned}
$$

$$
\bar{A}=\left(\begin{array}{c}
A_{d} \\
A_{d}^{2} \\
A_{d}^{3} \\
A_{d}^{4} \\
A_{d}^{5}
\end{array}\right), \bar{B}=\left(\begin{array}{ccccc}
B_{d} & 0 & 0 & 0 & 0 \\
A_{d} B_{d} & B_{d} & 0 & 0 & 0 \\
A_{d}^{2} B_{d} & A_{d} B_{d} & B_{d} & 0 & 0 \\
A_{d}^{3} B_{d} & A_{d}^{2} B_{d} & A_{d} B_{d} & B_{d} & 0 \\
A_{d}^{4} B_{d} & A_{d}^{3} B_{d} & A_{d}^{2} B_{d} & A_{d} B_{d} & B_{d}
\end{array}\right) .
$$

Selanjutnya, untuk menentukan kendali optimal pada waktu sampling $k, u(k)$, yang akan diaplikasikan pada sistem (3) digunakan fungsi biaya $J(X(k), U(k))$. Tujuan dari penelitian ini adalah merancang kendali yang membawa output sistem, dalam hal ini vektor state, menuju nol dengan menggunakan kendali/usaha semininimal mungkin. Oleh karena itu fungsi objektif yang digunakan terdiri atas dua suku. Suku pertama didefinisikan sebagai 
selisih antara prediksi state dengan trayektori referensi yakni vektor 0. Suku kedua adalah pembobotan kendali yang mewakili besarnya usaha kendali yang dilakukan, sehingga suku ini dapat direpresentasikan sebagai fungsi energi tiruan. Suku pertama diasumsikan semidefinit positif, dan suku kedua diasumsikan definit positif.

Fungsi objektif sepanjang horison prediksi $H_{p}=5$ diberikan oleh,

$$
J(X(k), U(k))=\sum_{j=1}^{5}\left(\begin{array}{c}
\hat{x}^{T}(k+j \mid k) Q \hat{x}(k+j \mid k) \\
+\hat{u}^{T}(k+j-1 \mid k) R \hat{u}(k+j-1 \mid k)
\end{array}\right),
$$

dengan $Q$ dan $R$ berturut-turut adalah matriks berukuran $4 \times 4$ dan $2 \times 2$.

Misalkan $\quad \bar{Q}=\operatorname{diag}(Q(1), Q(2), Q(3), Q(4), Q(5)) \quad \operatorname{dan} \quad \bar{R}=\operatorname{diag}(R(1)$, $R(2), R(3), R(4), R(5)$ ), persamaan (5) dapat di atas dapat dituliskan sebagai

$$
J(X(k), U(k))=X^{T}(k) \bar{Q} X(k)+U^{T}(k) \bar{R} U(k) .
$$

Selanjutnya, dengan mensubtisusi persamaan (4) ke persamaan (6), diperoleh

$$
\begin{aligned}
J(X(k), U(k)) & =x^{T}(k) \bar{A}^{T} \bar{Q} \bar{A} x(k)+2 x^{T}(k) \bar{A} \bar{Q} \bar{B} U(k) \\
& +U^{T}(k)\left(\bar{B}^{T} \bar{Q} \bar{B}+\bar{R}\right) U(k) .
\end{aligned}
$$

Diperhatikan bahwa pada setiap waktu sampling $k$, nilai $x(k)$ diketahui. Akibatnya, $x(k)$ merupakan parameter fungsi $J$ sedangkan argumen dari $J$ adalah $U(k)$.

Diperhatikan kembali bahwa $u_{1}(t)=q_{a}(t)-q_{a}^{0}$ dan $u_{2}(t)=q_{b}(t)-q_{b}^{0}$. Berdasarkan Tabel 2.1, diperoleh $u_{i_{\min }}=-1.63 \mathrm{~m}^{3} / \mathrm{h}, \quad u_{i_{\max }}=0.63 \mathrm{~m}^{3} / \mathrm{h}, i=1,2$. Sehingga himpunan fisibel aksi kendali $u(k+j-1)$ dan $j=1, \ldots, 5$ adalah $\Lambda=\{u(k+j-1)$ : $\left.\left[\begin{array}{l}-1.63 \\ -1.63\end{array}\right] \leq\left[\begin{array}{l}u_{1}(k+j-1) \\ u_{2}(k+j-1)\end{array}\right] \leq\left[\begin{array}{l}0.63 \\ 0.63\end{array}\right]\right\}$. Akibatnya, himpunan fisibel aksi kendali $U(k)$ adalah $\Omega=\prod_{j=1}^{5} \Lambda$. Masalah kendali optimal pada sistem empat tangki diberikan oleh

dengan kendala

$$
\min J(X(k), U(k))
$$

$$
U(k) \in \Omega \text {. }
$$

Misalkan $U^{\text {opt }}(k)$ adalah solusi optimal masalah optimisasi (5.10), maka keluaran sistem pada waktu sampling $k+1$ dalam hal ini vektor state $x(k+1)$ dihitung dengan mensubstitusi elemen peratama dari $U^{o p t}(k)$ pada persamaan (3).

\section{Hasil Simulasi}

Masalah kendali optimal yang disimulasikan adalah masalah regulator, yaitu membawa level air dari setiap tangki ke suatu nilai, dalam hal ini ke titik ekuilibriumnya, yaitu $h_{i}^{0}=0.6402 \mathrm{~m}, i=1,2$ dan $h_{i}^{0}=0.296 \mathrm{~m}, i=3,4$, yang ekuivalen dengan $x_{i}=0$, $i=1,2,3,4$, dengan periode kendali 1000 detik. Nilai-nilai awal yang digunakan adalah $h_{i}=$ $0.8042 \mathrm{~m}$ untuk $i=1,2$ dan $h_{i}=0.0960$ untuk $i=3,4$ yang ekuivalen dengan $x_{i}=0.2$ untuk $i=1,2$, dan $x_{i}=-0.2$ untuk $i=3,4$. Lebih jauh lagi, matriks bobot fungsi objektif $\operatorname{dipilih} Q(j)=\left(\begin{array}{cccc}0.01 & 0 & 0 & 0 \\ 0 & 0.01 & 0 & 0 \\ 0 & 0 & 0.01 & 0 \\ 0 & 0 & 0 & 0.01\end{array}\right)$ dan $R(j)=\left(\begin{array}{cc}0.001 & 0 \\ 0 & 0.001\end{array}\right), j=1, \ldots, 5$.

Hasil simulasi menggunakan Matlab diberikan oleh gambar berikut. 


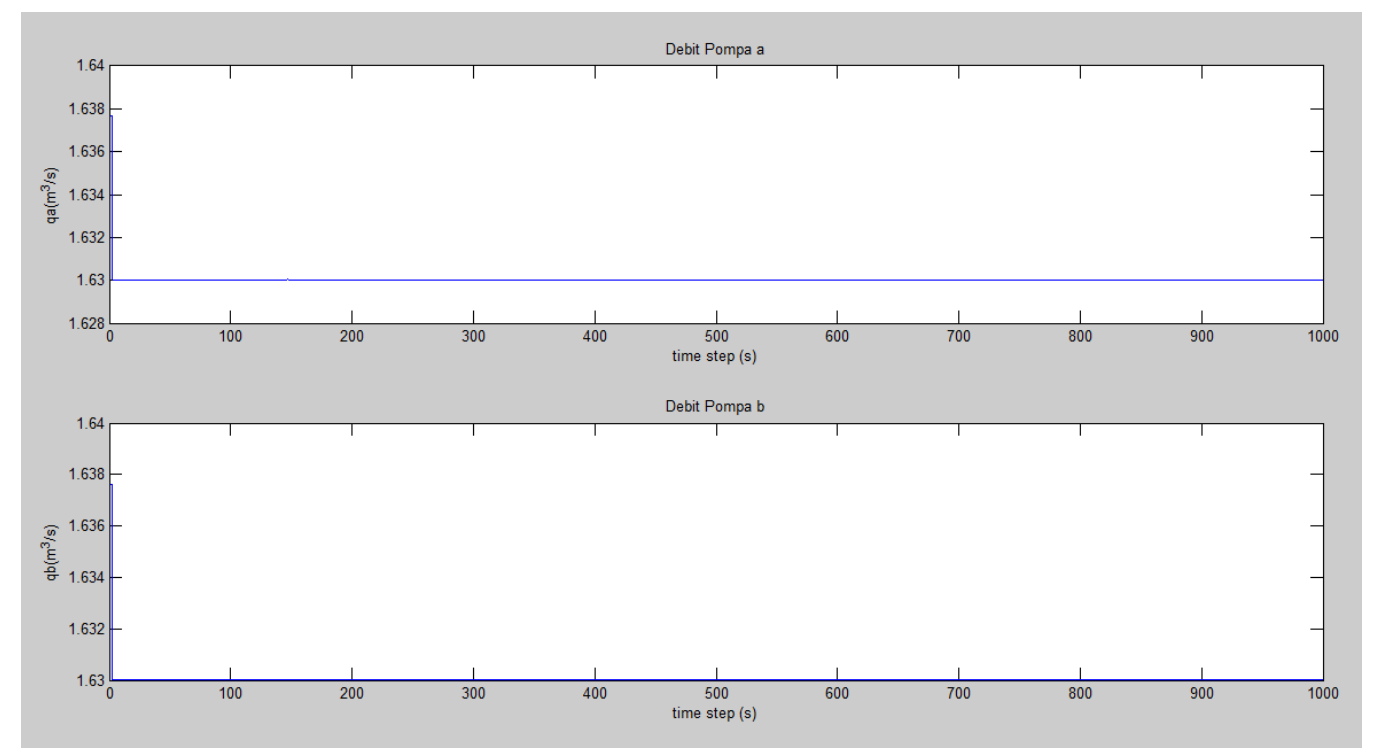

GAMBAR 2 Grafik Input Sistem

Gambar 2 di atas menunjukkan grafik input sistem $q_{a}$ dan $q_{b}$. Berdasarkan grafik di atas dapat dilihat bahwa nilai $q_{a}$ dan $q_{b}$ sepanjang time step berada pada rentang nilai yang diperbolehkan yakni $0 \mathrm{~m}^{3} / \mathrm{s} \leq q_{j} \leq 3.26 \mathrm{~m}^{3} / \mathrm{s}, j=a, b$. Hal ini menunjukkan bahwa perancangan kendali yang dilakukan dapat memenuhi kendala pada sistem. Garfik output sistem diberikan oleh Gambaar 3 di bawah ini.

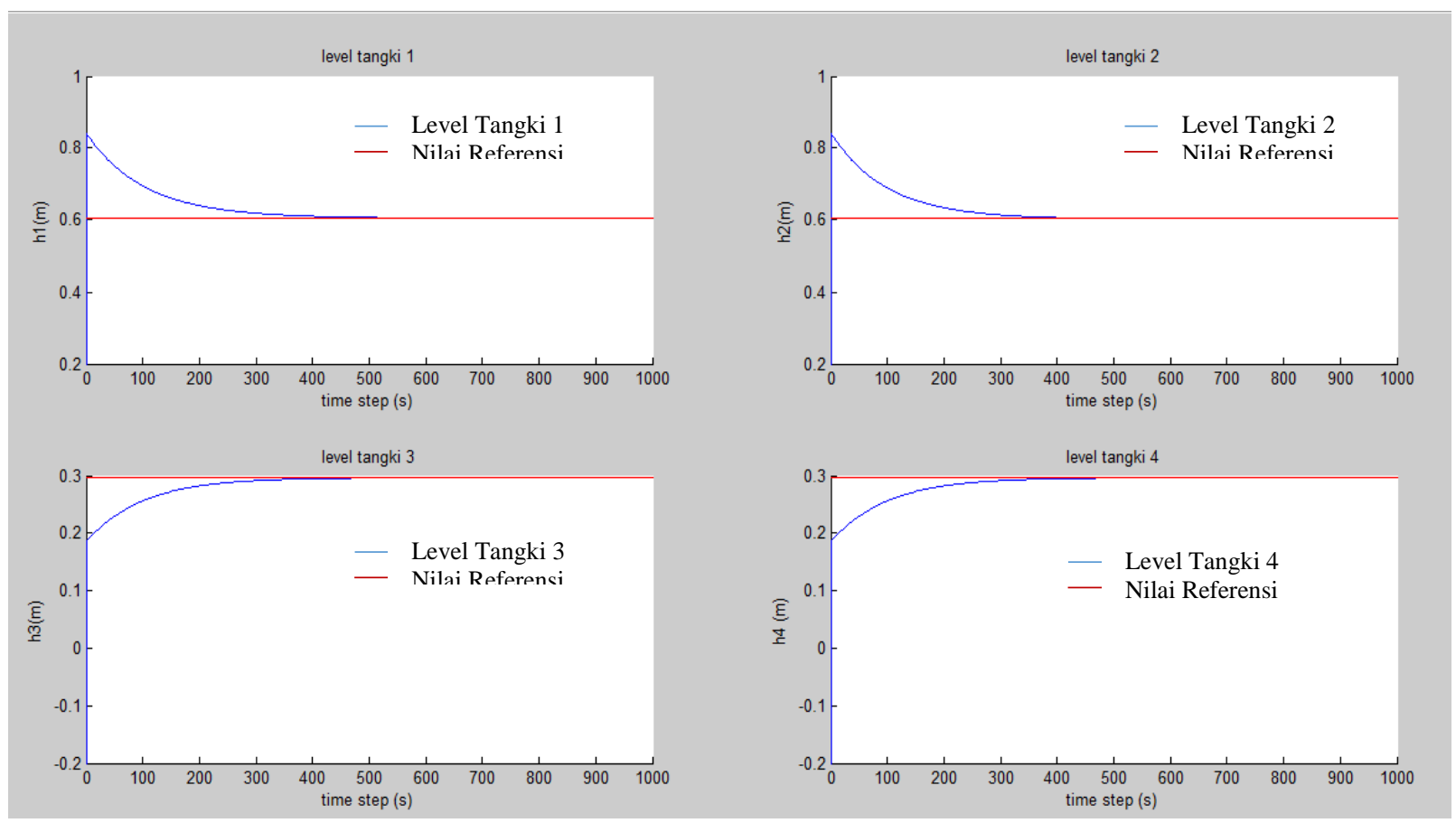

GAMBAR 3 Grafik Output Sistem

Berdasarkan gambar di atas dapat dilihat bahwa semua level tangki $h_{i}, i=1,2,3,4$ mampu dibawa menuju level ekuilibrium. Hal ini menunjukkan bahwa kendali optimal yang 
ditentukan dengan menggunkan teknik kendali model prediktif mampu membawa output ke nilai yang diinginkan dalam hal ini menuju level ekuilibrium.

\section{Kesimpulan}

Berdasarkan hasil penelitian yang disajikan di atas, dapat diambil kesimpulan bahwa sistem kendali yang dirancang mampu membawa level setiap tangki menuju nilai yang diinginkan dan kendali optimal yang digunakan berada pada batasan sistem yang diperbolehkan. Hal ini menunjukkan bahwa teknik kendali model prediktif sangat cocok untuk diaplikasikan pada sistem empat tangki.

Pada penelitian ini bobot matriks fungsi objektif yang digunakan ditentukan secara trial and error. Hal ini memungkinkan bahwa performa sistem kendali yang dirancang masih bisa ditingkatkan dengan memilih bobot matriks yang lebih tepat. Untuk tujuan ini penelitian akan dilanjutkan dengan merancang kendali pada sistem empat tangki menggunakan teknik kendali model prediktif berbasis particle swarm optimization untuk memperoleh bobot matriks yang lebih tepat sehingga performa sistem kendali yang dirancang lebih optimal.

\section{Ucapan Terima Kasih}

Ucapan terima kasih saya sampaikan kepada LPPM STKIP PGRI Bangkalan yang telah mendanai penelitian ini.

\section{Daftar Pustaka}

[1] Johansson, K. H., Horch, A., Wijk, O., Henrik, K., Alex, J., Hansson, A., 2000. Teachning Multivariabel Control Using The Quadrupple-Tank Pocess.

[2] Khalid, U., Shah, Y. A., Qamar, S., Gohar, W., Riaz, R., \& Shah, W. A. (2014). Flow and Level Control of Copled Four Tanks System Using Artificial Neural Network. American Journal of Computation, Communication and Control, 1(2), 30-35.

[3] Maciejowski, J. M. (2002). Predictive Control with Constraints. London, U.K.: PrenticeHall.

[4] Marzaki, M. H., Jalil, M. H., Shariff, H. M., \& Adnan, R. (2014). Comperative Study of Model Predictive Controller (MPC) and PID COntroller on Regulation Temperature for SSISD Plant. 2014 IEEE 5th Control and System Graduate Research Colloquium (hal. 136-140). Shah Alam, Malaysia: IEEE.

[5] Salem, F., \& Mosaad, M. I. (2015). A Comparison between MPC and Optimal PID Controllers: Case Studies. Michael Faraday IET International Summit: MFIIS-2015 (hal. 59-65). Kolkata: MFIIS .

[6] Selamat, N. A., Daud, F. S., Jaafar, H. I., \& Shamsudin, N. H. (2015). Comparison of LQR and PID Controller Tuning Using PSO for Coupled Tank System. 2015 IEEE 11th International Colloqium on Signal Processing \& its Applications (CSPA2015) (hal. 46-51). Kuala Lumpur: IEEE.

[7] Venkat, A.N., Hiskens, I.A., Rawlings, J.B., Wright, S.J.,(2008) Distributed MPC Strategies with Application to Power System Automatic Generation Control. IEEE Transactions on Control Systems Technology, 16(6), 1192-2206 